\section{Tethering the tide}

\section{T. L. Shaw examines the prospects for harnessing tidal energy in the Severn Estuary}

F ACED with a possible world tuel I shortage, the UK Department of Energy (DEN) is taking stock of domestic energy sources. Together with industry, it has already provided money for scientific and technical studies on the contribution four 'renewable' sources-wave, solar, geothermal and wind-could make to meeting future demands. It is now looking at the part tidal power could play.

The DEN's recently-released Energy Paper number 23, which discusses three commissioned reports on harnessing tidal power in the Severn Estuary, concludes that although tidal schemes are technically feasible, cost and the long time estimated for construction may rule them out. Nevertheless, studies to identify one or more schemes for wider appraisal are now being seriously considered.

The tides have the particular advantage of far greater energy density than the other renewable energy sources. In the Severn Estuary, for example, tidal energy is thirty times denser than power derived from average waves on the UK's Atlantic seaboard. Individual tidal schemes could produce many thousands of megawatts of electricity but, for maximum benefit, they would have to be integrated efficiently with other (essentially thermal) generating plant.

This enormous potential could be harnessed by building a dam to separate part of the coastal inlet from the sea. Turbines that might resemble conventional hydro-electric propeller machines would be set in fully sub-

T. L. Shaw is in the Department of Civil Engineering, University of Bristol. spectively.

\section{Recent studies}

merged tubes passing through the barrage. A ditference in water level either way across the barrage (during flood and ebb tide) would create fiow through these tubes and so an electrical output from the slowly rotating turbines.

In the Severn Estuary, the UK has perhaps the best site in the world for producing electricity from tidal power. At least $10 \%$ and as much as $20 \%$ of the UK's present electrical needs could be met from a barrage either within the estuary $(10 \%)$ or seaward in the Bristol Channel (20\%). These percentages are comparable with those currently supplied by nuclear installations and oil and gas-fired stations re-

But this is not simply a case of one electrical source competing against another. Each has characteristics which influence its most efficient hence preferred use: nuclear stations, for example, should run continuously, whereas gas turbines are best run in short bursts at times of high demand. The output of aerogenerators is fairly regular over a period of hours and maybe days while that of wave generators may be consistent on an even longer scale. Tidal output suffers from being intermittent but it is accurately predictable. There is no reason, however, why each source, provided that it can be commercially developed with respect to its operating value, should not contribute to the total generating network.

Last year the DEN commissioned two investigations into aspects of the Severn barrage. The questions the investigations set out to answer were: is construction and closure of a barrage

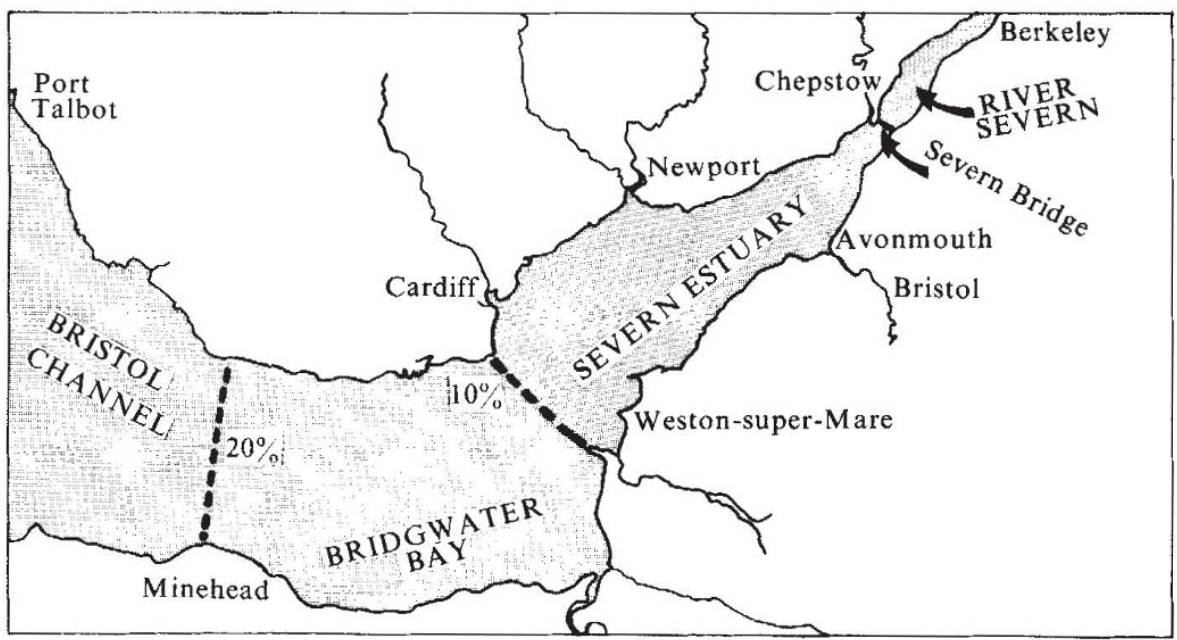

technically feasible? how long would it take to build? what would be the likely cost? and what would be the effect of the barrage and its operation on tidal range? They were issued respectively to the Netherlands Engineering Consultants Foundation (NEDECO), which has great knowledge in maritime affairs especially coastal protection, and to the UK Department of the Environment's Hydraulics Research Station (HRS), which, since it was established some 30 years ago, has worked extensively on coastal hydraulics.

For their studies both NEDECO and HRS chose to consider barrages in positions between Cardiff and Westonsuper-Mare, where $10 \%$ of the UK's present electrical demand could be produced. Most attention was paid to proposals by Professor Eric Wilson of Salford University (the simple singlebasin, tide-related scheme) and myself (the more complex two-basin arrangement providing storage and giving power by day as required. Summaries of each study are as follows.

\section{NEDECO}

In the absence of adequate field data, NEDECO was obliged to make a number of assumptions about hydrodynamic conditions at the chosen barrage site, in particular data describing wave climate. The serious lack of adequate geological and sedimentological information was met by surveys carried out by the UK Institute of Geological Sciences. It identified exposed limestones and marls over a much greater proportion of this part of the estuary than the previous scant scientific data had suggested. Localised fine deposits, mainly sand and shingle are thought to be shallow, implying a firm foundation throughout for a barrage.

Based on "the impressive experience obtained in the planning and execution of the Delta Works (in Holland) together with the immense increase in know-how and expertise of recent years in the offshore industry," NEDECO is optimistic that civil engineering aspects of the barrage could be carried out satisfactorily, though it appears to have underestimated the magnitude of the challenge successfully met by British industry of placing concrete caissons in $150 \mathrm{~m}$ of water in the remote and exposed North Sea, compared with the task of siting correspondingly much smaller units in no more than $30 \mathrm{~m}$ of sheltered water in the Severn Estuary.

But the siting of caissons for the barrage raises some problems not met in the North Sea, in particular the strong currents that accompany the 
high tides. The positioning and sinking of caissons in currents exceeding 3 metres per second could prove hazardous, but given proper planning they could be placed during slack water 'windows' which occur frequently and predictably.

Doubts also exist on the accuracy of NEDECO's estimates of extreme wave heights at the chosen barrage site. Unfortunately those local measurements that have been made are for such short periods that the validity of statistical extrapolation is questionable. Another factor is the apparently sheltered position of the barrage compared with that of the one longestablished wave recorder $100 \mathrm{~km}$ seawards. In the absence of other evidence, however, NEDECO's estimates cannot yet be dismissed.

Extra cost, NEDECO claims, will have to be incurred in building offshore-dykes to protect the turbines in the single-basin barrage from direct wave attack. If a two-basin scheme is adopted, however, the problem need not arise: the second basin would essentially serve the purpose of offshore dykes.

NEDECO estimates that the civil engineering task alone for the twobasin scheme will require four years of preliminary study and 16 years to build. This could be taken as sufficient to rule out the scheme on economic grounds. But it does agree that the timescale could be shortened, though with an increase in capital cost. By contrast, the UK construction industry feels that a timescale of about eight years, similar to that of most thermal plant, is realistic.

An alternative to help save on interest charges, would be to secure some energy from the scheme long before completion, increasing it as the scheme advances. The full output capacity of the scheme then would not be suddenly available to the network, and would permit efficient integration. Hence 16 years may not be unreasonable, though the various electrical merits of phased construction of a barrage are not yet clear; studies well advanced at the University of Bristol, funded by the Science Research Council, are exploring the possibilities. The concept of a twobasin barrage scheme developed first to operate in the 'single-basin' mode, as discussed earlier, may make good sense. NEDECO's study did not consider phased integration.

\section{Hydraulics research station}

The general lack of field data also made it difficult for HRS to define its problems, especially the seaward boundary conditions for its study's two-dimensional mathematical model.
Coastal and offshore tide modelling has moved a long way forward in the past five years, since it was recognised that local boundary changes can have effects at a considerable distance depending on their extent and the local tidal behaviour. Although earlier models, including that used by NEDECO, assumed that conditions at the seaward end of the Bristol Channel would not be unchanged by a barrage, HRS included the Celtic and Irish Seas in its model.

It is perhaps unfortunate that the 'large area' model of HRS predicts that the barrage will marginally amplify the tides whereas 'small area' models suggest the opposite. The right answer must be found, not least because, as matters now stand, the accuracy of both is under question.

But these doubts hide two aspects of the work of HRS. First, that it is something of a pioneering exercise in its own right and deserves recognition as such even if deficiencies later emerge. Secondly, an increase or decrease of tidal amplitude by up to 1 metre or so is sufficiently small in real terms to conclude at this stage that a barrage operating in the region Cardiff-Weston will not destroy the natural energy it is designed to harness. Although it must be a matter of some urgency to resolve why different mathematical models give different answers, and in particular to produce a model giving the right answers, it would only be wasteful to repeat these studies without knowing where the barrage might be sited, and understanding pump and turbine operation and induced oscillations (seiches) in the enclosed basin(s).

When reporting 'The situation in 1975', Energy Paper number 23 quotes that the Secretary of State's Advisory Council on Research and Development for Fuel and Power (ACORD) and the DEN came to the opinion that "in view of the uncertainties surrounding some of the aspects of the studies (of the barrage, as previously carried out by others), a more vigorous examination should be undertaken of certain key technical questions in order to clarify the situation further".

Of the three questions posed, the work of NEDECO and HRS should have answered two to the satisfaction of ACORD and the DEN. I hope that the third, namely "what would be the environmental consequences, and could they be quantified in cost terms?", will also be answered in similarly sufficient detail by the book An Environmental Appraisal of the Severn Barrage (second edition).

The next step is aptly stated by NEDECO: "The chance exists that we could contribute towards the
- The future for tidal energy in Britain has at last been clarified. There
have been strong calls for further studies by the House of Commons Select Committee on Science and Technology in its fourth report published last week and at the Secretary of State for Energy's 'Forum on the Severn Barrage', held in Bristol the week before.

Although the potential of the tides and the consequences of a barrage are fairly well understood, gaps in knowledge remain. The Select Committee, which has come out in support of tidal energy ahead of the other renewable sources, proposes that an independent Severn Barrage Committee, composed of technical, financial and administrative experts, be set up to assess Severn Barrage schemes and deliver a studied opinion to the Secretary of State. It highlights the unresolved problems of choosing a barrage location and method of operation and suggests that other studies should also be done. Outline costings, provisional construction methods and timescales should be sought by a "fairly early date ... to command general agreement".

The Secretary of State's 'Forum' provided the DEN with first-hand evidence on most of the many relevant topics, for example energy cost/benefit estimates, environmental consequences and the widespread employment, industrial, commercial and recreational merits of the project. Though opposition was scarcely evident, many speakers were cautious because so much remains unclear. Summing up Mr Benn, the Secretary of State, said that all relevant interests must be represented in the next important phase of project definition and that a staged approach allowing for reappraisal of points was essential. (The case for a pilot installation has wide support.)

While the DEN may not altogether deserve the Select Committee's criticism of being "excessively timid" about tidal energy, its scale of research funding must increase 100 -fold if these unified calls for action are to be answered. The national benefits at stake ought to make it easy for a cabinet to persuade the government to provide the still-modest sum now needed.

creation of a very clean type of energy production, the value of which can only increase because of its increasing scarcity on a worldwide scale". British industry is ready to contribute towards these investigations.

The capital cost estimate of up to $£ 4,000$ million quoted in Energy Paper number 23 might imply an expensive power station, but current unit costs for other plant tend to refute this. However, simple comparisons are dangerous when like objects are not being equated. It is much better that the next phase of study of the barrage should be carried out to identify its real electrical (and other) benefits before economic judgments are reached. A comprehensive but objective programme for the next 18 months is needed. 